\title{
Study on the Personnel Training Mode of Measurement and Control Technology and Instrument Specialty in Application-oriented Universities

\author{
Yunhui Hao ${ }^{1, a^{*}}$, Congbo Luo ${ }^{1, b}$ and Yanli Yang ${ }^{1, \mathrm{c}}$ \\ ${ }^{1}$ Changchun Sci-Tech University, Changchun Jilin China \\ ahuihui_06_09@163.com, bluocongbo13@163.com, cyangyanli1010w@163.com \\ * The corresponding author
}

Keywords: Measurement and Control Technology and Instrument; Personnel training mode; Application-oriented universities; university-enterprise cooperation

\begin{abstract}
The training target of application-oriented universities is to train applied talents, but the current personnel training mode is unsuitable. This paper introduced the development course and status of Measurement and Control Technology and Instrument specialty, and put out some measures to improve the students' practical ability, such as university-enterprise cooperation and establishing a reasonable teaching evaluation system. It has guiding significance to professional construction.
\end{abstract}

\section{Introduction}

Measurement and Control Technology and Instrument specialty, which is the secondary discipline of Instrument Science and Technology, is established earlier in China. Modern Measurement and Control Technology and Instrument has combined optics, mechanics, electrics, computer. and it is developing in the direction of intellectualization, integration, miniaturization and remote. So the requirements for measurement and control professionals have become higher and higher, the specialty is facing opportunities and challenges, and it is necessary to recognize the status of Measurement and Control Technology and Instrument specialty and analyze the reasons of this status. The purpose of application-oriented institutes is to train talents with high application ability, which is different from research-type universities, so establishing the training mode of Measurement and Control Technology and Instrument specialty in application-oriented institutes is very important for the development of the specialty.

\section{Development Course of Measurement and Control Technology and Instrument}

Tianjin University is the first school set up Measurement and Control Technology and Instrument specialty in China. After the founding of the People's Republic of China in 1949, the development of China's economy is fast, the demand for measurement and control is strong, so Tianjin University set up Precision Mechanical Instrument specialty in 1952. After that, Optical Instrument specialty was set up in Zhejiang University, and the university engaged many well-known experts as teachers. In the same year, Harbin Institute of Technology had engaged experts of the Soviet Union to teach the postgraduate students of Precision Instrument specialty. With the further development of economic construction, the demand for professionals of instrumentation was becoming bigger and bigger, so more and more colleges set up this kind of specialty, such as Tsinghua University, Shanghai Jiao Tong University, Changchun Institute of Optics and Mechanics and Beihang University. Before the beginning of "cultural revolution", more than 30 colleges and universities in China had set up more than 10 instrument specialties [1].

Because more and more institutions of higher learning had set up this kind of specialties, the need of establishing a specialized agency to manage this specialty was very urgent, so the National Instrument Textbook Compilation and Review Committee was set up in Tianjin University in 1963. The duty of the committee is studying the specialty systematically to seeking better development of the specialty. At this time, there were three specialties under instrument specialty, namely Precision Instrument, 
Automation Instrument and Optical Instrument, and the talent training model still fellow the education model of the Soviet Union [2]. Because of the "cultural revolution", China's politics, economy and culture were dealt a heavy blow, and basic teaching and research activities cannot be carried out. After "cultural revolution", education activities resumed normal. In 1998, the Regular Institutions of Higher Education National Undergraduate Professional Directory was enacted, the eleven specialties of instrument such as Precision Instrument, Optical Technology and Photoelectric Instrument, Testing Technology and Instrument has been integrated into one specialty named Measurement and Control Technology and Instrument. It is the performance of transformation from specialist education to generalist education. In the 21th century, the subject setting of colleges and universities is uniformly managed by the education of the Ministry of Education of the People's Republic of China, and the Instrument Teaching Steering Committee was established, Tianjin University was the director unit.

\section{Development Status of Measurement and Control Technology and Instrument}

The origin of Measurement and Control Technology and Instrument is roughly divided into two situations, one is derived from the merger of other specialties, so it has solid foundation, has many good teachers, and the capacity for scientific research and teaching research are strong. The other is setting up a new specialty, so its foundation is poor, faculty is shortage, the capacity for scientific research and teaching research are poor, and it is easily eliminated because of the lack of competitiveness in similar specialties. But this specialty in most universities belongs to the second situation [3].

Because of the need of construction, economy and scientific research, Measurement and Control Technology and Instrument has developed rapidly, the number of universities which set up this specialty from 96 in 2000 to 257 in 2009, and the number of students increased from 27600 to 85700 . At present, there are about 300 universities in China have set up this specialty, the number of the specialty has nearly quadrupled, and a large number of talents have been sent to all walks of life. The number of universities set up this specialty is more and more, but the number of students is fewer and fewer, so some universities lower the admission line, the gap of students between universities at different levels.

On the other hand, with the development of science and technology, the requirement for technical personnel of measurement and control is higher and higher, and the measurement and control technology has combined with light, machine, electricity and computer, which is greatly different from the traditional measurement. So the obtain employment of graduates from Measurement and Control Technology and Instrument in different levels of universities has very big difference. The jobs of Measurement and Control Technology and Instrument specialty are not more than Automation specialty and Internet of Things specialty. Table 1 shows the recruitment situation of these three specialties in Beijing.

Table 1 The recruitment situation of the three platforms in Beijing in the first half of June 2018

\begin{tabular}{|l|l|l|l|}
\hline & 51 job.com & Zhaopin.com & ChinaHR.com \\
\hline $\begin{array}{l}\text { Measurement and Control Technology } \\
\text { and Instrument specialty }\end{array}$ & 100 & 13 & 10 \\
\hline Automation specialty & 821 & 556 & 752 \\
\hline Internet of Things specialty & 300 & 42 & 142 \\
\hline
\end{tabular}

Fig. 1 shows the green brand professionals of different education levels. Green brand professional refers to the demand growth major with continuously high salary and employment rate and low unemployment rate. Software Engineering, Network Engineering and Communication Engineering have been green brand professionals for three years. 


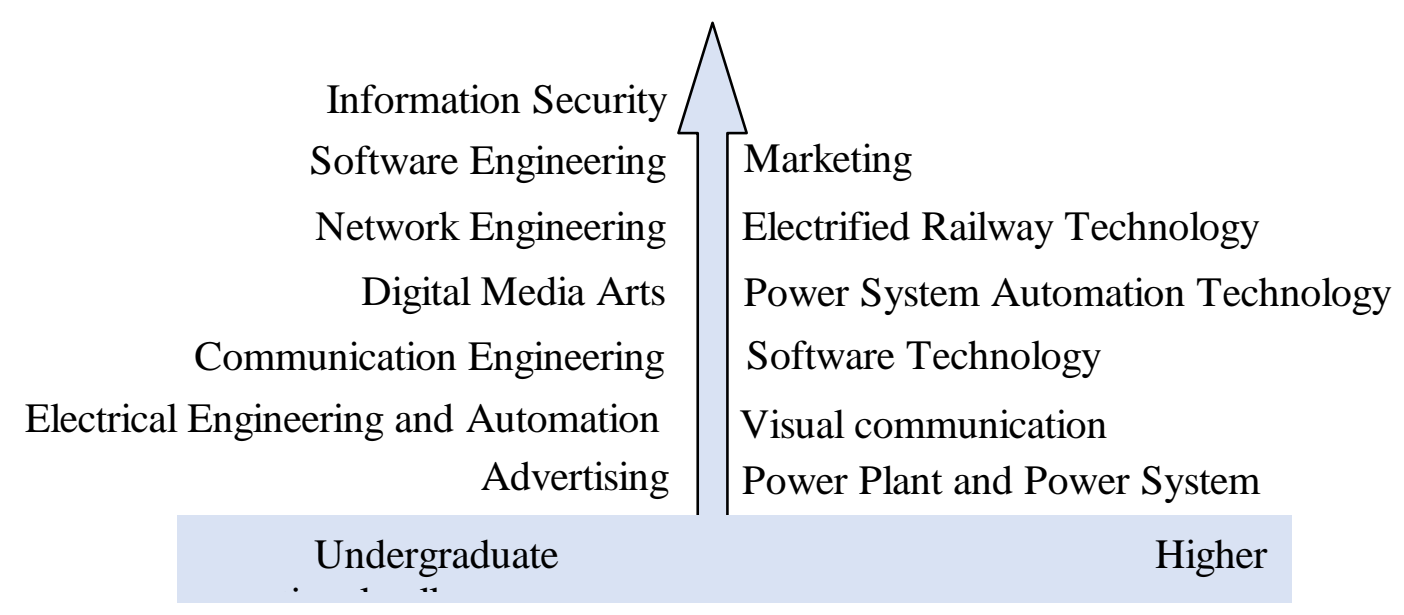

Figure 1. Finite Green brand professionals in 2017

Fig. 2 shows the red brand professionals of different education levels. Red card major refers to the major with large unemployment rate, and low employment, salary and job satisfaction. Fine Art and Music Performance have been red brand professionals for three years. Although the Measurement and Control Technology and Instrument specialty does not belong to green brand professional, it has never been a red brand professional.

\begin{tabular}{r|r} 
History \\
Music Performance \\
Biotechnology \\
Law \\
Fine Arts \\
Biological Engineering
\end{tabular} \mid $\begin{aligned} & \text { Law Affairs } \\
& \text { Chinese Education } \\
& \text { Graph and Image Making } \\
& \text { Primary Education } \\
& \text { Accounting Computerization }\end{aligned}$

Figure 2. Finite Red brand professionals in 2017

The regional employment situation of Measurement and Control Technology and Instrument specialty is very different, the demand of northeast area is small, but the demand of developed areas such as Beijing, Shanghai and Guangdong is bigger, and the treatment is also better.

\section{Reasons for the Status of Measurement and Control Technology and Instrument Specialty}

The Talent Training Plan is not Consistent with the Training Target, and the Curriculum is not reasonable. The development of measurement and control equipment and instruments is in urgent need of research talents with innovative ability and R \& D ability. However, the demand for applied talents for maintenance, operation and sales equipment is greater. The personnel training target in application-oriented undergraduates is to train applied technique-oriented professionals with high practical ability, which is different from research-oriented unversities. But the training pan still follow the training pan for specialized education, which tends to theoretical research, so the curriculum is also not conducive to the cultivation of application ability.

Out of Social Needs. Serving local economic and social development is the role that universities should play, but relative to the speed of technological updating, the teaching contents, teaching materials and experimental installation in universities updated too slowly. Most teachers lack social practical experience and do not pay attention to the needs of social development. After entering the 
society, students find that what they have learned in university is useless and the technology they used is not learned before, so some people think that going to college is useless.

Lack of Practice. The improvement of application ability requires a lot of practice, but many universities lack understanding of the importance of practical teaching, even though they have already recognized the importance, due to the limitation of conditions, environment, foundation and other factors, they also choose to wait and see and perfunctory, and still give priority to theoretical teaching. Even if there are conditions to provide students with the opportunity to experiment, there is also a great difference between experiment and the actual work, and lack of practical activities that can effectively improve students' practical ability and the ability to deal with practical problems.

Insufficient Teachers. Because of the limit of funding conditions and geographical conditions, some universities are difficult to employ professional teachers with rich experience and strong scientific research ability. The proportion of teachers to meet the practice training is not high, a large number of young teachers have entered universities after graduation from universities (mainly teaching and research universities), and lack specialized training in practical teaching, they are not competent for relevant practical guidance. This is very unfavorable to the cultivation of application-oriented talents.

The Teaching Methods to Meet the Training of High Quality Applied Talents are still Short and Backward. The shortage of multimedia teaching facilities cannot meet the needs of teachers in teaching environments such as case teaching and practical demonstration, and restricts the enthusiasm of teachers in educational and teaching reform. Many courses basically remain the traditional teaching mode of lecture, imparting knowledge to students by teachers in language, and students rarely interact with teachers. Training simulation venues limit students' more opportunities to develop practical skills. The existing training facilities are far from meeting the needs of teaching practice.

The Teaching Evaluation Mechanism is not Perfect. Application-oriented universities should pay attention to assess the ability to analyze and solve problems of students, which reflects the application of theoretical knowledge. But the current teaching evaluation mechanism cannot meet the needs of practical teaching reform, cannot play a positive role in strengthening the practical teaching link and encouraging reform in the practical teaching link, on the contrary there is a restrictive tendency [4]. Especially, the evaluation of the students' practical courses and the conversion of teachers' practical teaching workload need further exploration.

\section{Improvement Measures for Application-oriented Personnel Training}

The personnel training objective of application-oriented universities is to train graduates with strong practical skills, and to serve local economic and social development. Therefore, various measures should be taken to realize the fundamental purpose of cultivating students' practical ability and improving students' competitiveness.

Formulate Talent Training Plan Which is Consistent with the Training Target. Should increase the intensity of practical teaching and integrate theoretical teaching content. The course sequence should be reasonably arranged according to the professional requirements, important courses should set up corresponding experiments according to the teaching progress and after the end of courses design of courses should be designed for comprehensive training. After the completion of all courses, comprehensive training for the project will be arranged.

Strengthen School-Enterprise Cooperation. It is very important for application-oriented universities to understand the needs of society. Fig. 3 shows ten aspects of cooperation with companies. 
Figure 3. Finite

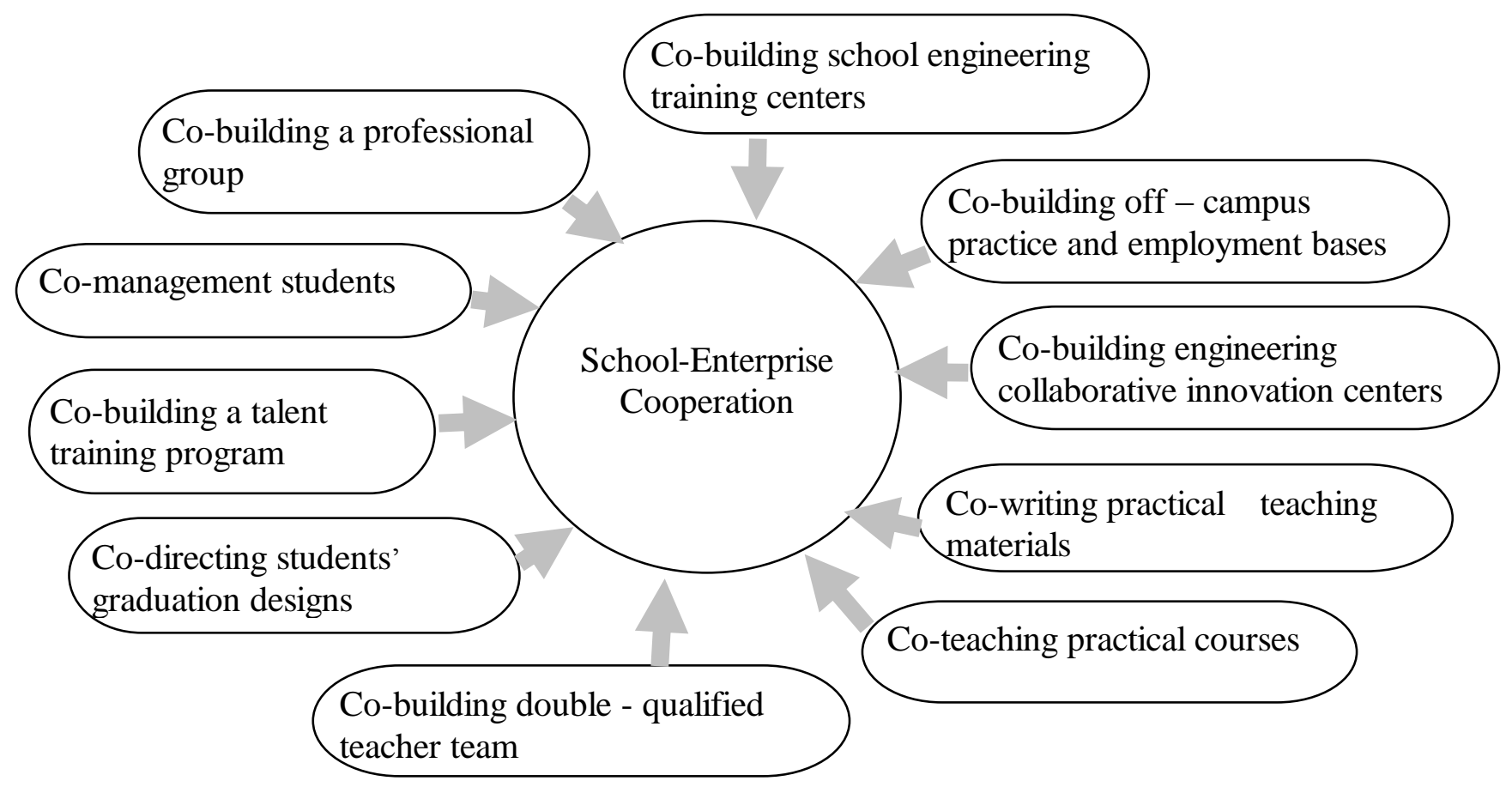

The measures for integration of production and education

Changchun Sci-Tech University has cooperated with Suzhou DECHUANG Measurement and Control Technology Co., Ltd. for two years. Enterprise engineers are hired to direct engineering training as practical teachers and young teachers in university are hired to be assistant to help these engineers. On the one hand, they know cutting-edge technology and the practical needs of the enterprises, so it is easy to combine with reality, and the students have higher learning enthusiasm. One the other hand, the content of engineering training is what the students will do during their graduation practice, so when they begin to work it is easy to adapt and complete their task. In addition to inviting business personnel to teach in school, the teachers also be sent to the company to learn the technology, that not only improves the practical ability of young teachers, but also be beneficial to train double qualified teachers who possess the quality of theoretical teaching and practical teaching [5]. Changchun Sci-Tech University not only build the DUCHUANG Machine Vision Training Center which can meet the need of engineering training, but also build some off-campus practice base with DECHUANG, and arrange students' graduation practice in the way of on-post internship. During the internship, the management and education of the students are mainly done by the enterprise, but teachers in university should keep in touch with the management of the enterprise, and pay attention to the dynamics of students.

Graduation design is the most comprehensive practice in the undergraduate stage, and it is an examination of students' comprehensive ability. The graduation designs of application-oriented universities should contact with practice and eliminate obsolete content. Hiring enterprise engineers to direct graduation design has practical significance.

Cooperation with companies is the best method to make up for the lack of universities, it can improve the practical conditions without paying too much.

Reform the Teaching Methods. Training applied talents is the target of application-oriented universities, and teaching should focus on the application of knowledge, so teaching methods which are good for development of practical ability should be adapted, such as demonstration method, discussion method and so on. Micro-course teaching also helps students to understand.

Establish a Reasonable Teaching Evaluation System. Teaching Evaluation System includes two aspects, one is the evaluation of teachers, and the other is the evaluation of students. Universities should define the assessment criteria and methods, encourage innovation, encourage reform, and 
implement job responsibilities to improve the performance of practical teaching. Evaluation of students should consider the results and the processes of dealing with problems.

\section{Summary}

With the development of economy and society, the demand for applied talents is increasing. Application-oriented universities should take measures to reform the current personnel training mode, and establish a talent training mode which is suitable for training applied talents. Changchun Sci-Tech University has cooperated with DECHUANG Measurement and Control Technology Co., Ltd., and achieved better results, but still need further study and discussion to improve the talent training model.

\section{Acknowledgements}

Jilin Province Educational Science Planning Topics, "Research on Application-oriented Talents Training Model of Measurement and Control Technology and Instrument Specialty in Private Universities", GH16574.

\section{References}

[1] Y.C. Tao: Shandong Industrial Technology, Vol.16 (2016), p.285. (In Chinese)

[2] B. Xu: Electronic Technology \& Software Engineering, Vol.24 (2016), p.133. (In Chinese)

[3] H.L. Pan, J. Zhou and X.Y. Cao: Journal of Science of Teacher' College and Universit, Vol. 35 (2015) No.1, p.78. (In Chinese)

[4] Information on https://baike.sogou.com

[5] Information on https://baike.baidu.com

[6] Peng L, Fang W. Heterogeneity of Inferring Reputation of Cooperative Behaviors for the Prisoners' Dilemma Game [J]. Physica A: Statistical Mechanics and its Applications, 2015, 433: 367-378. 